\title{
Instrumen Penilaian Hasil Belajar Berbasis Higher Order Thinking Skill pada Tema Kepemimpinan
}

\section{Ni Komang Gina Astuti ${ }^{*}$, I Ketut Dibia ${ }^{2}$, I Komang Sudarma ${ }^{3}$}

\author{
1,2,3 Pendidikan Dasar, Universitas Pendidikan Ganesha, Singaraja, Indonesia
}

\section{ART ICLE IN F O}

Article history:

Received June 20, 2021

Revised June 26, 2021

Accepted July 30, 2021

Available online August 25, 2021

Kata Kunci:

Hasil Belajar, Order Thinking

Sikll, instrumen

\section{Keywords:}

Learning Outcomes, Order

Thinking Skill, instrument

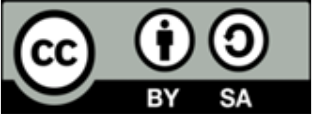

This is an open access article under the CC BY-SA license.

Copyright $(2021$ by Author. Published by Universitas Pendidikan Ganesha.

\begin{abstract}
A B S T R A K
Masih banyaknya guru yang tidak menggunakan instrumen penilaian sesuai dengan syarat instrumen penilaian dan belum mampu membuat instrumen penilaian yang sesuai dengan prosedur. Penelitian ini bertujuan untuk menghasilkan instrumen penilaian hasil belajar kelas VI pada tema kepemimpinan yang berupa soal tes berbasis Higher Order Thinking Skills yang valid dan reliabel. Penelitian ini merupakan penelitian pengembangan dengan model 4D oleh Thiagarajan yang terdiri dari tahap mendefenisikan, tahap merancang, tahap mengembangkan dan tahap menyebarluaskan. Keempat tahap model ini dijadikan pedoman dalam memvalidasi instrumen yang dikembangkan. Data dikumpulkan menggunakan metode tes. Instrumen tes yang digunakan ialah berupa tes objektif untuk menilai hasil belajar siswa Hasil penelitian ini yaitu uji validitas isi sebesar 1.00 termasuk kategori sangat tinggi, uji validitas butir dihasilkan 27 butir tes valid, uji reliabilitas tes sebesar 0,72 termasuk kriteria tinggi, analisis daya beda soal diperoleh $14,8 \%$ soal dengan kriteria kurang baik, 55,5 \% dinyatakan cukup baik, 14,8\% terdapat dengan kriteria baik, dan $14,8 \%$ dinyatakan sangat baik, analisis tingkat kesukaran diperoleh hasil terdapat 9 soal dengan kategori mudah dan 12 soal dengan kategori sedang kemudian 6 soal dengan kategori sukar, hasil analisis kualitas pengecoh diperoleh hasil terdapat 85 pengecoh kriteria baik dan 5 pengecoh kriteria kurang baik. Berdasarkan hasil penelitian, dapat disimpulkan bahwa instrumen yang penilaian hasil belajar tema 7 berbasis Higher Order Thinking valid dan layak digunakan sebagai instrumen penilaian pada siswa.
\end{abstract}

\section{A B S TRA C T}

There are still many teachers who do not use an assessment instrument following the requirements of the assessment instrument and have not been able to make an assessment instrument that is following the procedure. This study aims to produce an instrument for assessing learning outcomes for class VI on the theme of leadership in the form of valid and reliable test questions based on Higher Order Thinking Skills. This research is development research with the 4D model by Thiagarajan which consists of the defining stage, designing stage, developing stage, and disseminating stage. The four stages of this model are used as guidelines invalidating the developed instrument. Data were collected using the test method. The test instrument used is an objective test to assess student learning outcomes. The results of this study are the content validity test of 1.00 including the very high category, the item validity test resulted in 27 valid test items, the test reliability test of 0.72 including high criteria, analysis of discriminating power questions obtained $14.8 \%$ of questions with poor criteria, $55.5 \%$ were declared quite good, $14.8 \%$ were found with good criteria, and $14.8 \%$ were stated to be very good, the analysis of the level of difficulty obtained the results that there were 9 questions with easy categories and 12 questions in the medium category than 6 questions in the difficult category, the results of the quality analysis of distractors obtained the results that there were 85 good criteria distractors and 5 bad criteria distractors. Based on the results of the study, it can be concluded that the instrument that assesses outcomes of theme 7 based on Higher Order Thinking is valid and feasible to be used as an assessment instrument for students. 


\section{PENDAHULUAN}

Pembelajaran dikatakan berhasil jika tujuan pembelajaran dapat tercapai secara maksimal. Kegiatan pembelajaran seluruh siswa harus dilibatkan sehingga dapat mengaktifkan siswa dalam belajar (Ariani, 2017; Hewi \& Shaleh, 2020; (Hartini et al., 2014; Hartuti, 2015). Untuk menghujudkan hal tersebut guru harus mampu memfasilitasi siswa agar memiliki kemampuan berpikir tingkat tinggi atau higher order thinking skills (HOTS) karena itu merupakan salah satu kemampuan dalam ranah kognitif yang saat ini menjadi perhatian dalam kurikulum 2013 (Fadzam \& Rokhimawan, 2020; Nisa et al., 2018). Higher Order Thinking Skill dipandang sebagai kemampuan untuk menghubungkan, memanipulasi dan mentransformasikan pengetahuan dan pengalaman yang sudah dimiliki untuk berpikir secara kritis dan kreatif dalam rangka memecahkan masalah (Eveline et al., 2019; Supranoto, 2018). Kemampuan berpikir tinggi (Higher Order Thinking Skills) merangsang siswa untuk menginterpretasikan, menganalisis atau bahkan mampu memanipulasi informasi sebelumnya sehingga tidak monoton (Fadzam \& Rokhimawan, 2020; Khotimah \& Sari, 2020). Berpikir tingkat tinggi ditunjukkan dengan peserta didik dapat memberikan penilaian yang bijaksana atau memberikan kritik yang beralasan (Kaya et al., 2018; Silberman et al., 2021; Sk \& Halder, 2020). Serta, kemampuan siswa dalam memecahkan masalah dalam belajar maupun kehidupan mereka (Kwangmuang et al., 2021; Zulfiani et al., 2020). Kemampuan ini merupakan tuntutan kurikulum 2013 yaitu siswa tidak hanya mengetahui, memahami dan mengaplikasikan tetapi dituntut dapat menganalisis, mengevaluasi bahkan mencipta (Nasihin, 2016; Sanjiwana et al., 2015; Sofyan, 2016).

Namun pada kenyataannya, permasalahan yang terjadi saat ini yaitu masih banyak guru yang kesulitan membuat instrument penilaian belajar siswa (Arif, 2016; Pratiwi, 2017). Permasalahan lain yaitu beberapa guru tidak menggunakan instrumen penilaian melainkan hanya mengamati kegiatan pembelajaran untuk mengumpulkan data (Mundia Sari \& Setiawan, 2020; Primasari et al., 2020). Selain itu masih banyak guru belum mampu mengembangkan perangkat pembelajaran dengan baik (R. Nugroho, 2018; Wirdaningsih et al., 2017). Hal ini juga diperkuat oleh data yang diperoleh dari observasi dan wawancara di SD Negeri 4 Pemuteran diketahui bahwa guru kesulitan dalam menentukan instrumen yang tepat untuk digunakan dalam proses pembelajaran, orientasi pembelajaran masih berada pada level berpikir tingkat rendah dibuktikan dengan instrumen penilaian guru masih berada pada tingkatan C1 sampai C3, belum adanya instrumen penilaian HOTS yang sudah teruji validitas dan reabilitasnya pada tema kepemimpinan. Permasalahan tersebut jika tidak di atasi maka akan membuat proses pembelajaran menjadi tidak baik dan siswa tidak akan memiliki kemampuan HOTS. Maka dari itu, diperlukan solusi untuk mengatasi permasalahan tersebut. Salah satu solusi yang dapat dilakukan adalah dengan mengembangkan instrumen penilaian HOTS. Penilaian adalah proses atau kegiatan yang berkesinambungan untuk mengumpulkan informasi mengenai proses dan hasil belajar peserta didik dalam rangka membuat sebuah keputusan berdasarkan pertimbangan tertentu (A. S. Nugroho \& Mawardi, 2021). Diperlukan peran guru dalam melatih siswa sehingga memiliki kemampuan berpikir tingkat tinggi yang menjadi tuntutan kurikulum 2013 (Dewi, 2018; Hewi \& Shaleh, 2020; Mega et al., 2015; Mulyadin, 2016). Agar memiliki kemampuan berpikir tingkat tinggi (HOTS), guru dapat memberikan soal tes berbasis HOTS untuk melatih siswa agar terbiasa berpikir tingkat tinggi. Soal tes berbasis Higher Order Thinking Skill (HOTS) dapat membantu siswa mengembangkan kemampuan dalam berpikir tingkat tinggi (Andoko, 2020; Nguyễn \& Nguyễn, 2017; Pratiwi, 2017; Saraswati \& Agustika, 2020; Wei et al., 2021).

Beberapa penelian sebelumnya menyatakan bahwa soal berbasis HOTS sangat penting dilakukan untuk mengukur ketercapaian dalam proses pembelajaran (Prastikawati et al., 2021; Umami et al., 2021). Asesmen HOTS layak diterapkan untuk siswa sekolah dasar (Herawati et al., 2014). Temuan lain menyatakan bahwa soal berbasis HOTS sangat penting dilakukan untuk mengukur ketercapaian pembelajaran (Kwangmuang et al., 2021; Prastikawati et al., 2021; Umami et al., 2021). Instrumen sikap sosial tematik siswa SD kelas IV layak digunakan (Candra et al., 2018). instrumen penilaian proyek berbasis model discovery learning dapat digunakan untuk mengukur keterampilan pemecahan masalah peserta didik (Sukmasari \& Rosana, 2017). Bahan ajar dan instrumen penilaian IPA pada Kurikulum 2013 yang dikembangkan terbukti efektif (Purnomo \& Wilujeng, 2016). Namun belum ada kajian yang berfokus pada instrumen HOTS pada tema kepemimpinan di sekolah dasar. Kebaruan penelitian ini dibandingkan penelitian-penelitian sebelumnya ialah penelitian ini berfokus pada pengembangan instrumen penilaian hasil belajar berbasis HOTS pada tema kepemimpinan di sekolah dasar. Tujuan penelitian ini adalah mengembangkan instrument penilaian hasil belajar berbasis Higher Order Thinking Skills pada tema kepemimpinan di sekolah dasar kelas VI. Adanya pengembangan instrument berbasis HOTS dapat membantu guru dalam mengembangkan keterampilan berpikir tingkat tinggi siswa. 


\section{METODE}

Jenis penelitian ini adalah penelitian pengembangan. Prosedur atau tahapan pengembangan yang digunakan dalam penelitian ini adalah menggunakan model 4D terbagi atas empat tahap yaitu Define, Design, Develop, dan Disseminate (Agung, 2014). Model ini digunakan karena sistematis dan mudah dipahami. Subyek penelitian ini adalah seluruh siswa kelas VI SD Negeri 4 Pemuteran dan SD Negeri 5 Pemuteran Kecamatan Gerokgak. Adapun desain penelitian disajikan pada gambar 1. Teknik yang digunakan dalam mengumpulkan data yaitu wawancara, metode kuesioner/angket, dan metode tes. Observasi dan wawancara dilakukan dengan tujuan untuk menggali informasi kendala terkait proses pembelajaran dan ketersediaan instrumen yang sudah digunakan oleh guru. Tes digunakan untuk mengetahui pemahaman siswa. Instrumen yang digunakan untuk mengumpulkan data yaitu kuesioner. Instrumen yang digunakan dalam mengumpulkan data yaitu kuesioner. Hasil penelitian akan dianalisis validitas, reliabilitas, daya beda, tingkat kesukaran, kualitas pengecoh respon siswa. Instrumen yang telah dirancang untuk mengumpulkan data selanjutnya diuji coba terlebih dahulu agar mengetahui kevalidan instrumen. Instrumen penelitian dianalisis dengan menggunakan uji validitas isi dan uji validitas butir tes. Uji validitas isi dilakukan menggunakan rumus Gregory. Uji reliabilitas juga dilakukan untuk mengukur tingkat keajegan tes. Selain itu dilakukan juga analisis daya beda, analisis tingkat kesukaran, dan analisis kualitas pengecoh.

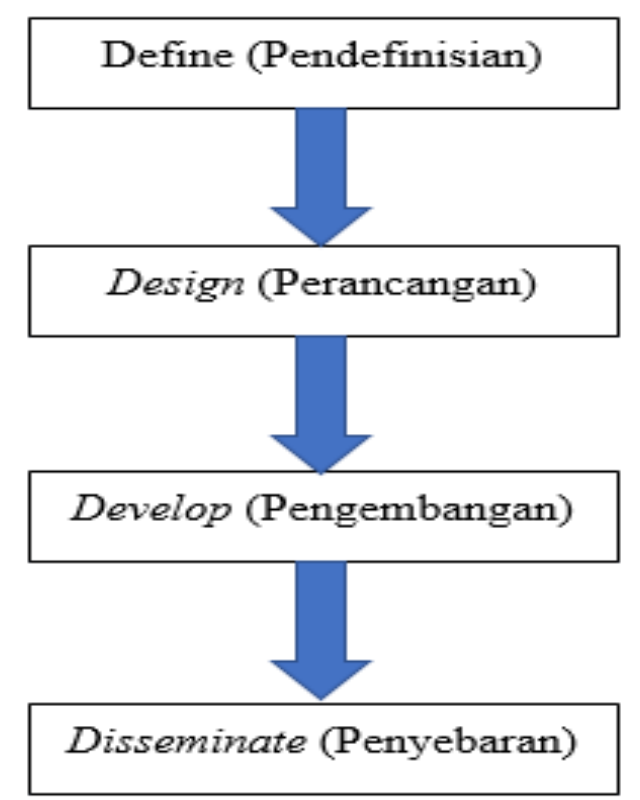

Gambar 1. Desain Penelitian 4D

\section{HASIL DAN PEMBAHASAN}

\section{Hasil}

Prosedur atau tahapan pengembangan yang digunakan dalam penelitian menggunakan model 4D terbagi atas empat tahap yaitu Define, Design, Develop, dan Disseminate. Adapun pemaparan prosedur tersebut yaitu sebagai berikut. Tahap awal yang dilakukan adalah define. Pada tahap ini kegiatan yang dilakukan yaitu observasi, wawancara, analisis kebutuhan, analisis karakteristik peserta didik, dan analisis tugas. Berdasarkan hasil analisis, kebutuhan yang diperlukan oleh guru yaitu instrument penilaian yang dapat mengukur hasil belajar siswa. Berdasarkan hasil analisis karakteristik siswa masih banyak siswa yang memiliki semangat belajar yang rendah dan memiliki tingkat kecerdasan yang kurang. Berdasarkan hasil analisis tugas ditemukan bahwa siswa hanya diberikan lembar kerja peserta didik (LKPD) dalam pembelajaran. Pada tahap kedua yaitu design (perancangan) dilakukan analisis kompetensi inti dan kompetensi dasar, kemudian menyusun indikator-indikator yang sesuai kompetensi dasar, dan menyusun rancangan awal instrumen yang dilengkapi dengan kisi-kisi instrumen. Kisi-kisi yang dihasilkan yaitu kisi-kisi soal hasil belajar ada tema kepemimpinan. Pada tahap dilakukan penyusunan instrumen soal pilihan ganda (obyektif), pembuatan lembar validasi serta pencetakan instrumen. Adapun kisi-kisi yang telah dikembangkan tersaji pada Tabel 1. 
Tabel 1. Kisi-kisi instrumen hasil belajar berbasis HOTS

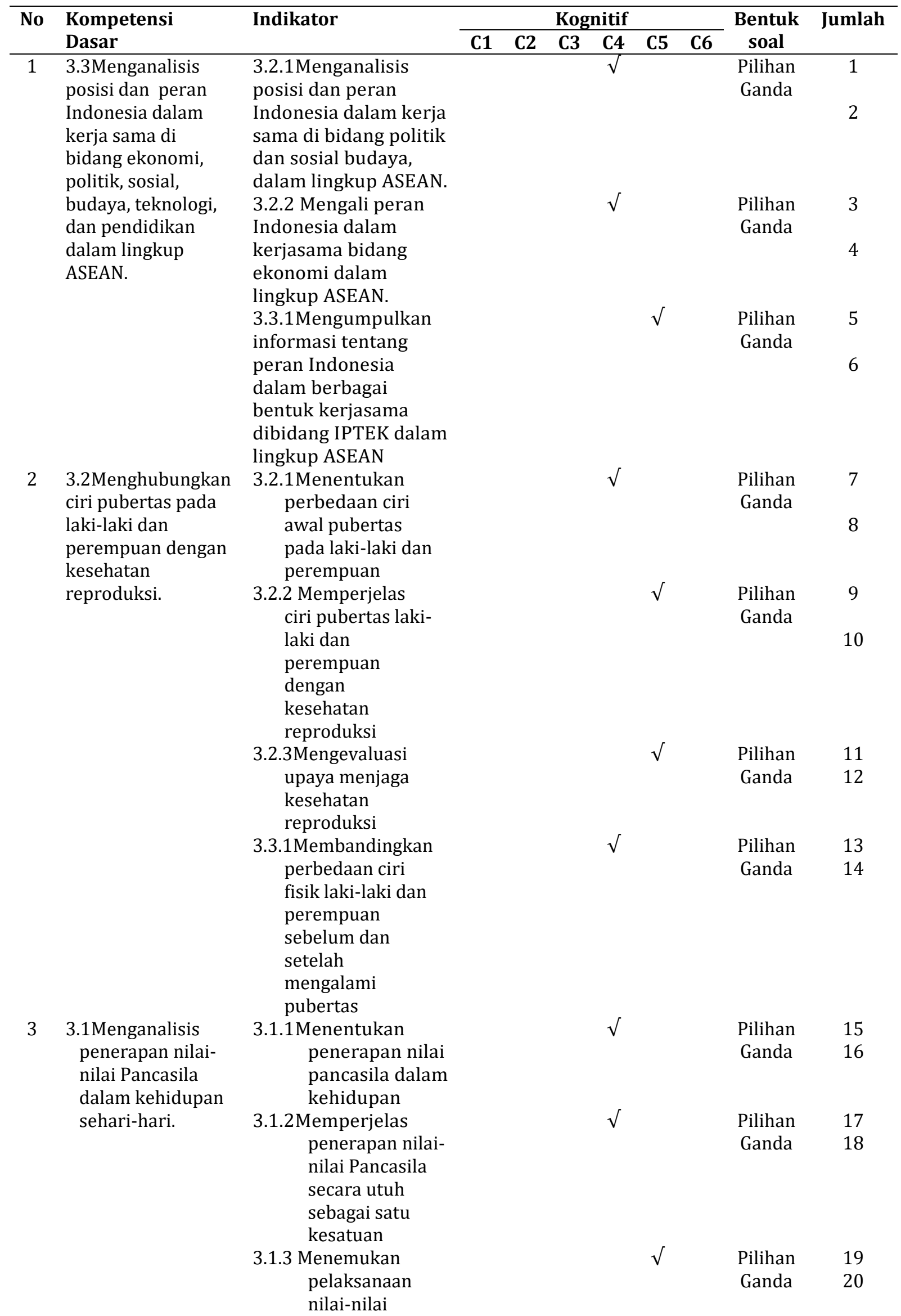




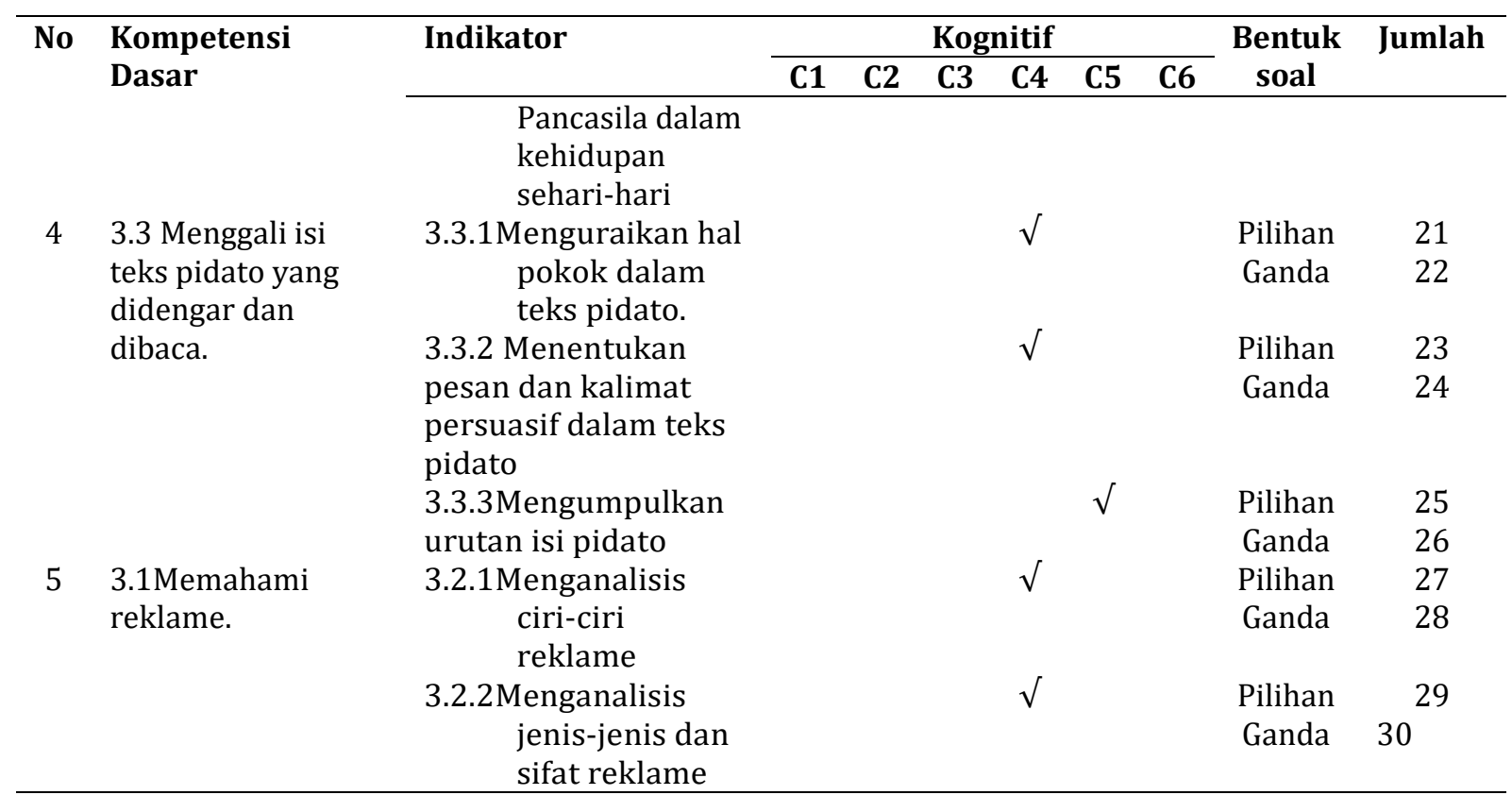

Tahap ketiga yaitu develop. Pada tahap ini dilakukan pengembangan instrumen penilaian hasil belajar tema kepemimpinan berbasis higher order thingking skills. Setelah instrumen dikembangkan, kemudian diuji oleh para ahli. Tahap ini terbagi atas expert appraisal dan developmental testing. Expert Appraisal (Validasi Ahli) merupakan tahap yang harus dilakukan dan dilalui sebelum instrumen yang dikembangkan digunakan atau diberikan kepada siswa. Tahap validasi ahli ini menggunakan uji analisis validasi isi berupa lembar validasi yang diberikan kepada ahli, yang nantinya ahli akan memberikan penilaian dan masukan yang berguna untuk perbaikan dan penyempurnaan produk yang dihasilkan. Hasil penilaian dari uji ahli didapatkan bahwa dari 30 pernyataan yang dikembangkan dinyatakan relevan semua. Berdasarkan hasil perhitungan, indeks validitas isi instrument tersebut adalah 1,00 dan jika dikonvensikan maka instrumen hasil belajar berbasis HOTS pada tema kepemimpinan yang diujikan berada pada kriteria "Sangat Tinggi". Tahap selanjutnya Developmental Testing dilaksanakan dengan beberapa tahap yaitu uji respon siswa dengan uji coba kelompok kecil. Uji coba kelompok kecil dilakukan dengan jumlah 75 responden.

Berdasarkan hasil perhitungan validitas butir didapatkan hasil dari 30 soal yang diuji cobakan, sebanyak 3 soal tidak valid dan 27 soal valid. Soal yang tidak valid menandakan bahwa kualitas soal tersebut tidak baik. Dengan demikian, soal yang tidak valid sejumlah 3 dinyatakan gugur dan tidak akan digunakan sebagai instrumen penilaian. Selanjutnya dilakukan uji reliabilitas dengan menggunakan butir soal yang dinyatakan valid. Berdasarkan hasil perhitungan, koefisien reliabilitas 27 butir soal diperoleh KR-20 = 0,72 atau jika dikonversikan berada pada tingkatan “Tinggi”. Setelah dilakukan reliabilitas kemudian dilakukan uji daya beda. Berdasarkan hasil perhitungan uji daya beda, sesuai dengan kriteria untuk uji daya beda 4 butir soal dengan kriteria sangat baik, 4 butir soal dengan kriteria baik, 15 butir soal dengan kriteria cukup baik, dan 4 soal dengan kriteria kurang baik. Jumlah keseluruhan butir soal yaitu sebanyak 27 butir soal. Setelah uji daya beda selanjutnya dilakukan tingkat kesukaran. Berdasarkan hasil analisis tingkat kesukaran sebanyak 27 butir soal, diperoleh 6 soal dengan kategori sukar yaitu 22,2\%, 12 soal dengan kategori mudah yaitu 44,4\%, dan 9 soal dengan kategori sedang yaitu 33\%. Setelah melakukan uji perhitungan tingkat kesukaran selanjutnya dilakukan uji kualitas pengecoh. Hasil uji kualitas pengecoh menunjukkan $\mathrm{P}>5 \%$ sebanyak 5 dan $\mathrm{P} \leq 5 \%$ sebanyak 85.Berdasarkan hasil analisis data, maka dapat disimpulkan bahwa instrumen yang penilaian hasil belajar berbasis HOTS pada tema kepemimpinan valid dan layak digunakan dikarenakan beberapa faktor diantaranya ialah sebagai berikut.

Pertama, instrumen yang penilaian hasil belajar berbasis High Order Thinking Skill pada tema kepemimpinan sudah memenuhi syarat instrumen penilaian yang baik. Syarat instrumen penilaian yang baik yaitu valid, reabilitas, dan praktis. Prinsip umum yang wajib dipenuhi dalam penilaian adalah valid, mendidik, berkesinambungan, bermakna, menyeluruh, dan berorientasi pada kompetensi (Hulukati \& Rahmi, 2020; Novitasari \& Wardani, 2020). Instrumen yang baik dan layak digunakan harus memiliki validitas, reliabilitas, dan nilai kepraktisan (Gaol et al., 2017; Zuliani et al., 2017). Instrumen yang telah dikembangkan telah melalui uji dan melakukan revisi produk sesuai saran dan masukan dari para ahli sehingga instrumen penilaian yang dikembangkan menjadi sempurna. 
Kedua, instrumen yang penilaian hasil belajar berbasis High Order Thinking Skill pada tema kepemimpinan dikarenakan instrumen ini dapat digunakan untuk memperoleh informasi yang diinginkan. Instrumen merupakan alat ukur yang dapat digunakan untuk menilai sesuatu dalam rangka pengumpulan data dalam memperoleh informasi yang diinginkan (Adjii, 2019; Gaol et al., 2017; Yusup, 2018). Penilaian dalam pembelajaran wajib dilakukan untuk mengetahui informasi secara berkala tentang perkembangan siswa selama proses pembelajaran berlangsung. Penilaian dalam pembelajaran dapat dilakukan melalui tes. Adanya tes bertujuan untuk mengetahui ketercapaian pemahaman yang di miliki setiap siswa (Hülya Kaya PhD et al., 2017; Paul \& Elder, 2013). Untuk mencapai tujuan tersebut, maka setiap butir tes harus disusun sesuai dengan tujuan pembelajaran dan memiliki tingkat penalaran yang tinggi (HOTS) (Afshara \& Masoud Rahimi, 2014; Kavenuke et al., 2020). Guru memerlukan instrumen untuk memperoleh informasi tentang perkembangan siswa dalam proses pembelajaran. Pada penelitian pengembangan instrumen hasil belajar berbasis HOTS pada tema kepemimpinan memiliki kriteria validitas sangat tinggi dan reliabilitas tinggi sehingga instrumen ini sudah tepat dan layak digunakan sebagai alat evaluasi atau penilaian pembelajaran yang akurat pada tema kepemimpinan kelas VI sekolah dasar.

Temuan penelitian ini memperkuat temuan penelitian sebelumnya yang menyatakan bahwa instrumen penilaian yang valid dan reliabel, layak digunakan dan dapat digunakan untuk mengukur kemampuan siswa (Arif, 2016; Solihah et al., 2020; Yusup, 2018). Instrumen penilaian HOTS sangat penting dilakukan untuk mengukur ketercapaian dalam proses pembelajaran dan layak diterapkan untuk siswa sekolah dasar (Herawati et al., 2014; Prastikawati et al., 2021; Umami et al., 2021). menyatakan instrumen berbasis HOTS dapat meningkatkan kemampuan berpikir tingkat tinggi siswa (Anwar et al., 2020; Nisa et al., 2018) Kelebihan instrumen ini adalah dapat mengukur kemampuan HOTS siswa pada tema kepemimpinan kelas VI sekolah dasar. Penelitian ini diharapkan guru dapat mengembangkan instrumen yang baik agar dapat digunakan dalam proses pembelajaran. Implikasi penelitian ini yaitu instrumen penilaian berbasis HOTS yang dikembangkan ini dapat digunakan oleh guru untuk menilai hasil belajar siswa pada tema kepemimpinan. Implikasi penelitian ini yaitu instrumen ini juga dapat dijadikan sebagai pedoman untuk mengembangkan instrumen penilaian lainnya karena dengan adanya instrumen penilaian hasil belajar dapat membantu guru mengetahui kemampuan masing-masing siswa sehingga tujuan pembelajaran dapat tercapai dengan baik.

\section{SIMPULAN}

Instrumen penilaian hasil belajar berbasis Higher Order Thinking Skills pada tema kepemimpinan valid dan layak digunakan sebagai instrumen penilaian pada siswa. Instrumen ini dapat digunakan oleh guru untuk mengukur kemampuan siswa dalam proses pembelajaran.

\section{DAFTAR PUSTAKA}

Adjii, K. (2019). Instrumen penilaian kedisiplinan siswa sekolah menengah kejuruan. Assessment and Research on Education, 1(1). https://doi.org/10.33292/arisen.v1i1.19.

Afshara, H. S., \& Masoud Rahimi. (2014). The Relationship among Critical Thinking, Emotional Intelligence, and Speaking Abilities of Iranian EFL Learners. Procedia - Social and Behavioral Sciences, 136(9), 75-79. https://doi.org/10.1016/j.sbspro.2014.05.291.

Agung, A. A. G. (2014). Metodologi Penelitian Pendidikan. Aditya Media Publishing.

Andoko. (2020). Peningkatan Hots Dan Prestasi Belajar Melalui Metode Inkuiri Kelas 7C SMPN 1 Wonosobo Tahun Pelajaran 2018/2019. Spektra: Jurnal Kajian Pendidikan Sains, 6(1). https://doi.org/10.32699/spektra.v6i1.134.

Anwar, Y., Selamet, A., Huzaifah, S., \& Madang, K. (2020). Training in developing higher-order thinking based online test instrument for biology teachers in Sekayu City. Journal of Community Service and Empowerment, 1(3), 150-155. https://doi.org/10.22219/jcse.v1i3.12241.

Ariani, T. (2017). Pembelajaran Kooperatif Tipe Team Assisted Individualization (TAI): Dampak Terhadap Hasil Belajar Fisika Siswa. Jurnal Ilmiah Pendidikan Fisika Al-Biruni, 6(2), 169-177. https://doi.org/10.24042/jipfalbiruni.v6i2.1802.

Ariani, T. (2020). Analysis of Students' Critical Thinking Skills in Physics Problems. Physics Educational Journal, 3(1), 1-13. https://doi.org/10.37891/kpej.v3i1.119.

Arif, M. (2016). Pengembangan Instrumen Penilaian Mapel Sains melalui Pendekatan Keterampilan Proses Sains SD/MI. Ta'allum: Jurnal Pendidikan Islam, 4(1). https://doi.org/10.21274/taalum.2016.4.1.123-148. 
Candra, I., Sulistya, N., \& Prasetyo, T. (2018). Pengembangan Instrumen Sikap Sosial Tematik Siswa SD Kelas IV. Jurnal Ilmiah Sekolah Dasar, 2(4), 455. https://doi.org/10.23887/jisd.v2i4.16167.

Dewi, R. S. (2018). Kemampuan Profesional Guru Dan Motivasi Kerja Terhadap Kinerja Mengajar Guru Sekolah Dasar. Jurnal Administrasi Pendidikan, 25(1), 150-158. https://doi.org/10.17509/jap.v25i1.11581.

Drennan, J. (2010). Critical thinking as an outcome of a Master's degree in nursing programme. Journal of Advanced Nursing, 66(2), 422-431. https://doi.org/10.1111/j.1365-2648.2009.05170.x.

Erlin Eveline, Suparno, S., Ardiyati, T. K., \& Dasilva, B. E. (2019). Development of Interactive Physics Mobile Learning Media for Enhancing Students' HOTS in Impulse and Momentum with Scaffolding Learning Approach. Jurnal Penelitian \& Pengembangan Pendidikan Fisika, 5(2), 123-132. https://doi.org/10.21009/1.05207.

Fadzam, I. A., \& Rokhimawan, M. A. (2020). Analisis Materi Ipa Kelas Iv Tema Indahnya Kebersamaan Dengan HOTS. Jurnal Ilmiah Didaktika: Media Ilmiah Pendidikan Dan Pengajaran, 21(1). https://doi.org/10.22373/jid.v21i1.5970.

Gaol, P. L., Khumaedi, M., \& Masrukan, M. (2017). Pengembangan Instrumen Penilaian Karakter Percaya Diri pada Mata Pelajaran Matematika Sekolah Menengah Pertama. Journal of Research and Educational Research Evaluation, 6(1). https://doi.org/10.15294/jrer.v6i1.16209.

Hartini, T. I., Kusdiwelirawan, \& Fitriana, I. (2014). Pengaruh Berpikir Kreatif dengan Model Problem Based Learning (PBL) Terhadap Prestasi Belajar Fisika Siswa dengan Menggunakan Tes Open Ended. PII 3 (1). Jurnal Pendidikan IPA Indonesia, 3(1), 8-11. https://doi.org/10.15294/jpii.v3i1.2902.

Hartuti. (2015). Peran konsep diri, minat dan kebiasaan belajar peserta didik terhadap prestasi belajar fisika. Formatif: Jurnal Ilmiah Pendidikan MIPA, 5(2). https://doi.org/10.30998/formatif.v5i2.329.

Herawati, R., S, R. W., \& Hamdu, G. (2014). Pengembangan Asesmen Hots Pada Pembelajaran Berbasis Masalah Tema Bermain Dengan Benda-Benda Di Sekitar. PEDADIDAKTIKA: Jurnal Ilmiah Pendidikan Guru Sekolah https: //ejournal.upi.edu/index.php/pedadidaktika/article/view/4975.

Hewi, L., \& Shaleh, M. (2020). Refleksi Hasil PISA (The Programme For International Student Assesment): Upaya Perbaikan Bertumpu Pada Pendidikan Anak Usia Dini). Jurnal Golden Age, 4(01), 30-41. https://doi.org/10.29408/jga.v4i01.2018.

Hulukati, W., \& Rahmi, M. (2020). Instrumen Evaluasi Karakter Mahasiswa Program Pendidikan Guru Pendidikan Anak Usia Dini. Jurnal Obsesi: Jurnal Pendidikan Anak Usia Dini, 4(2). https://doi.org/10.31004/obsesi.v4i2.468.

Hülya Kaya PhD, B., Emine Şenyuva PhD, B., \& Gönül Bodur PhD, B. (2017). Developing critical thinking disposition and emotional intelligence of nursing students: a longitudinal research. Nurse Education Today, 48, 72-77. https://doi.org/10.1016/j.nedt.2016.09.011.

Ineson, E. M., Jung, T., Hains, C., \& Kim, M. (2013). The influence of prior subject knowledge, prior ability and work experience on self-efficacy. Journal of Hospitality, Leisure, Sport and Tourism Education, 12(1), 59-69. https://doi.org/10.1016/j.jhlste.2012.11.002.

Kavenuke, P. S., Kinyota, M., \& Kayombo, J. J. (2020). The critical thinking skills of prospective teachers: Investigating their systematicity, self-confidence and scepticism. Thinking Skills and Creativity, 37, 100677. https://doi.org/10.1016/j.tsc.2020.100677.

Kaya, H., Şenyuva, E., \& Gönül Bodur. (2018). The relationship between critical thinking and emotional intelligence in nursing students: A longitudinal study. Nurse Education Today, 68, 26-32. https://doi.org/10.1016/j.nedt.2018.05.024.

Khotimah, R. P., \& Sari, M. C. (2020). Pengembangan Lembar Kerja Peserta Didik Berbasis Higher Order Thinking Skills (HOTS) Menggunakan Konteks Lingkungan. Jurnal Aksioma, 9(3). https://doi.org/10.24127/ajpm.v9i3.2909.

Kwangmuang, P., Jarutkamolpong, S., Sangboonraung, W., \& Daungtod, S. (2021). The development of learning innovation to enhance higher order thinking skills for students in Thailand junior high schools. Heliyon, 7(6). https://doi.org/10.1016/j.heliyon.2021.e07309.

Mega, C., Pudjawan, K., \& Margunayasa, I. G. (2015). Analisis sikap sosial siswa kelas V pada pembelajaran dengan kurikulum 2013. Mimbar PGSD Universitas Pendidikan Ganesha, 3(1). https://doi.org/10.23887/jjpgsd.v3i1.5631.

Mulyadin. (2016). Implementasi Kebijakan Pembelajaran Tematik Terpadu Kurikulum 2013 di SDN Kauman 1 Malang dan SD Muhammadiyah 1 Malang. Jurnal Pendidikan Edutama, 3(2), 31-48. https://doi.org/10.30734/jpe.v3i2.35. 
Mundia Sari, K., \& Setiawan, H. (2020). Kompetensi Pedagogik Guru dalam Melaksanakan Penilaian Pembelajaran Anak Usia Dini. Jurnal Obsesi : Jurnal Pendidikan Anak Usia Dini, 4(2), 900. https://doi.org/10.31004/obsesi.v4i2.478.

Nasihin, S. (2016). Implementasi Kurikulum 2013 di MTs Yaqin 1 Kwang Rundun Kecamatan Jerowaru (Masalah dan Solusinya). Jurnal Studi Keislaman Dan Ilmu Pendidikan, 4(1), 56-86. https://doi.org/10.36088/palapa.v4i1.8.

Nguyễn, T. M. T., \& Nguyễn, T. T. L. (2017). Influence of explicit higher-order thinking skills instruction on students' learning of linguistics. Thinking Skills and Creativity, 26, 113-127. https://doi.org/10.1016/j.tsc.2017.10.004.

Nisa, N. A. K., Widyastuti, R., \& Hamid, A. (2018). Pengembangan Instrumen Assesment Higher Order Thinking Skill (HOTS) Pada Lembar Kerja Peserta Didik Kelas VII SMP. Prosiding Seminar Nasional Matematika Dan Pendidikan Matematika, 3(3), 543-556.

Novitasari, L., \& Wardani, N. S. (2020). Pengembangan Instrumen Sikap Toleransi Dalam Pembelajaran Tematik Kelas 5 SD. Jurnal Penelitian Tindakan Kelas Dan Pengembangan Pembelajaran, 3(1). https://doi.org/10.31604/ptk.v3i1.41-52.

Nugroho, A. S., \& Mawardi. (2021). Pengembangan Instrumen Penilaian Sikap Tanggungjawab dalam Pembelajaran Tematik di Sekolah Dasar. Jurnal Basicedu, 5(2), 808-817. https://doi.org/10.31004/basicedu.v5i2.825.

Nugroho, R. (2018). Pengembangan Perangkat Pembelajaran Dengan Pendekatan Contextual Teaching And Learning Untuk Meningkatkan Motivasi Dan Hasil Belajar Bagi Siswa Kelas Iv Sekolah Dasar. Jurnal Bidang Pendidikan Dasar, 2(2). https://doi.org/10.21067/jbpd.v2i2.2638.

Paul, R., \& Elder, L. (2013). Critical Thinking: Intellectual Standars Essential to Reassoning Well Within Every Domain of Human Thought, Part Two. Journal of Development Education, 37(1), 32-36. https://eric.ed.gov/?id=EJ1067273.

Prastikawati, E. F., Wiyaka, W., \& Budiman, T. C. S. (2021). Pelatihan Penyusunan Soal Bahasa Inggris Berbasis HOTS bagi Guru Bahasa Inggris SMP. Jurnal Pengabdian Masyarakat, 6(1). https: //doi.org/10.30653/002.202161.761.

Pratiwi, P. H. (2017). Pengembangan Modul Mata Kuliah Penilaian Pembelajaran Sosiologi Berorientasi HOTS. Cakrawala Pendidikan, 36(2). https://doi.org/10.21831/cp.v36i2.13123.

Primasari, I. F. N. D., Marini, A., \& Sumantri, M. S. (2020). Analisis Kebijakan Dan Pengelolaan Pendidikan Terkait Standar Penilaian Di Sekolah Dasar. Jurnal Basicedu, 3(2), 524-532. https://doi.org/10.31004/basicedu.v5i3.956.

Purnomo, H., \& Wilujeng, I. (2016). Pengembangan bahan ajar dan instrumen penilaian IPA tema Indahnya Negeriku penyempurnaan buku guru dan siswa kurikulum 2013. Jurnal Prima Edukasia, 4(1), 67-78. https://doi.org/10.21831/jpe.v4i1.7697.

Sanjiwana, P. P. C. M., Pudjawan, \& Margunayasa, I. G. (2015). Analisis Sikap Sosial Siswa Kelas V pada Pembelajaran dengan Kurikulum 2013. Jurnal PGSD Universitas Pendidikan Ganesha, 3(1), 11-18. https: //doi.org/10.23887/jjpgsd.v3i1.5631.

Saraswati, P. M. S., \& Agustika, G. N. S. (2020). Kemampuan Berpikir Tingkat Tinggi Dalam Menyelesaikan Soal HOTS Mata Pelajaran Matematika. Jurnal Ilmiah Sekolah Dasar Undiksha, 4(2). https: //doi.org/10.23887/jisd.v4i2.25336.

Silberman, D., Carpenter, R., Takemoto, J. K., \& Coyne, L. (2021). The impact of team-based learning on the critical thinking skills of pharmacy students. Currents in Pharmacy Teaching and Learning, 13(2), 116-121. https://doi.org/10.1016/j.cptl.2020.09.008.

Sk, S., \& Halder, S. (2020). Critical thinking disposition of undergraduate students in relation to emotional intelligence: Gender as a moderator. Heliyon, 6(11). https://doi.org/10.1016/j.heliyon.2020.e05477.

Sofyan. (2016). Pembelajaran Problem Based Learning dalam Implementasi Kurikulum 2013 di SMK. Jurnal Pendidikan Vokasi, 6(3), 260-271. https://doi.org/10.21831/jpv.v6i3.11275.

Solihah, A. N., Jubaedah, Y., \& Rifa'i, M. S. S. (2020). Pengembangan Instrumen Pengukuran Perkembangan Sosial-Emosional Anak Berbasis Home-Based Childcare. Widyadari, 6(1). https://doi.org/10.5281/zenodo.3517997.

Sukmasari, V. P., \& Rosana, D. (2017). Pengembangan penilaian proyek pembelajaran IPA berbasis discovery learning untuk mengukur keterampilan pemecahan masalah. Jurnal Inovasi Pendidikan IPA, 3(1), 101. https://doi.org/10.21831/jipi.v3i1.10468.

Supranoto, H. (2018). Pengembangan Soal HOTS Berbasis Permainan Ular Tangga pada Mata Kuliah Telaah Ekonomi SMA. Journal of Chemical Information and Modeling, 6(1), 103-110. https://doi.org/10.24127/pro.v6i1.1501. 
Umami, R., Rusdi, M., \& Kamid, K. (2021). Pengembangan Instrumen Tes Untuk Mengukur Higher Order Thinking Skills (Hots) Berorientasi Programme For International Student Asessment (Pisa) Pada Peserta Didik. JP3M: Jurnal Penelitian Pendidikan Dan Pengajaran Matematika, 7(1). https: //doi.org/10.37058/jp3m.v7i1.2069.

Wei, X., Lin, L., Meng, N., Tan, W., Kong, S. C., \& Kinshuk. (2021). The effectiveness of partial pair programming on elementary school students' Computational Thinking skills and self-efficacy. Computers and Education, 160, 104023. https://doi.org/10.1016/j.compedu.2020.104023.

Wirdaningsih, S., Arnawa, I. M., \& Anhar, A. (2017). Pengembangan Perangkat Pembelajaran Matematika Dengan Pendekatan Contextual Teaching And Learning Untuk Meningkatkan Kemampuan Pemecahan Masalah Peserta Didik Kelas XI. Jurna Nasional Pendidikan Matematika, 1(2). https://doi.org/10.33603/jnpm.v1i2.535.

Yusup, F. (2018). Uji Validitas dan Reliabilitas Instrumen Penelitian Kuantitatif. Jurnal Tarbiyah : Jurnal Ilmiah Kependidikan, 7(1), 17-23. https://doi.org/10.18592/tarbiyah.v7i1.2100.

Zulfiani, Suwarna, I. P., \& Sumantri, M. F. (2020). Science adaptive assessment tool: Kolb’s learning style profile and student's higher order thinking skill level. Jurnal Pendidikan IPA Indonesia, 9(2), 194207. https://doi.org/10.15294/jpii.v9i2.23840.

Zuliani, D., Florentinus, T. S., \& Ridlo, S. (2017). Pengembangan Instrumen Penilaian Karakter pada Siswa Kelas IV Sekolah Dasar. Journal of Research and Educational Research Evaluation, 6(1). https://doi.org/10.15294/jrer.v6i1.16207. 